\title{
ANÁLISE DAS MANIFESTAÇÕES PATOLÓGICAS NA ALVENARIA DO EDIFÍCIO CENTENÁRIO DA ESCOLA POLITÉCNICA DE PERNAMBUCO - POLI/UPE
}

\author{
SILVA, ALYX \\ Mestrando em Engenharia Civil \\ Escola Politécnica de Pernambuco \\ Pernambuco; Brasil \\ ados_pec@poli.br

\section{SANTOS, CYNTHIA} \\ Mestranda em Engenharia Civil \\ Escola Politécnica de Pernambuco \\ Pernambuco; Brasil \\ cjos_pec@poli.br
}

\author{
NASCIMENTO BARROS, EDENIA \\ Mestranda em Engenharia Civil \\ Escola Politécnica de Pernambuco \\ Pernambuco; Brasil \\ enb_pec@poli.br
}

\author{
LORDSLEEM JR, ALBERTO \\ Professor Associado e docente permanente \\ Escola Politécnica de Pernambuco \\ Pernambuco; Brasil \\ acasado@poli.br
}

\section{RESUMO}

Este trabalho objetiva apresentar investigações das manifestações patológicas (MP) das alvenarias do edifício centenário de fundação da Escola Politécnica da Universidade de Pernambuco. A metodologia da pesquisa contempla o levantamento externo das fachadas utilizando-se um Veículo Aéreo Não Tripulado (VANT). Enquanto na parte interna, o levantamento de subsídios foi realizado nos dois pavimentos da edificação por meio de inspeção visual; análise das causas; determinação da prioridade de intervenção pelo método GUT. Como resultado, foram identificados 4 tipos de MP: umidade, bolor, eflorescência e fissuras/ trincas, a partir da identificação foram elaborados mapa de danos das fachadas, identificação dos locais no interior do edifício que apresentaram as MP na alvenaria, propostas de recuperação e por fim um plano de manutenção preventivo. Foi concluído que na alvenaria do edifício houveram danos estéticos, e que a execução das medidas corretivas propostas pode garantir a inibição da evolução das MP na alvenaria evitando assim possíveis danos estruturais e que após as devidas correções se faz necessário ter um plano de manutenção preventiva, para que se façam manutenções periódicas, visto que o prédio já passou do tempo de vida útil (50 anos) e que precisa de cuidados especiais por se tratar de uma construção centenária.

Palavras-chaves: manifestações patológicas, alvenaria, edifício centenário, manutenções.

\begin{abstract}
This paper aims to present investigations of the pathological manifestations (PM) of the masonry of the centenary building of the Polytechnic School of the University of Pernambuco. The research methodology includes the external survey of the facades using an Unmanned Aerial Vehicle (UAV). While indoors, the subsidies were surveyed on both floors of the building by visual inspection; cause analysis; determination of intervention priority by the GUT method. As a result, 4 types of PM were identified: moisture, mold, efflorescence and fissures / cracks, from the identification were prepared map of damage of the facades, identification of the sites inside the building that presented the PM in the masonry, recovery proposals and finally a preventive maintenance plan. It was concluded that aesthetic damage was found in the masonry of the building, and that the implementation of the proposed corrective measures can ensure the inhibition of the evolution of PM in the masonry thus avoiding possible structural damage and that after the necessary corrections a preventive maintenance plan is necessary, for periodic maintenance, since the building is past its useful life (50 years) and needs special care because it is a century-old building.
\end{abstract}

Keywords: pathological, mansory, centenary building, corrective maintenance 
ISBN 978-65-86819-05-2

\section{INTRODUÇÃO}

O termo patologia é amplamente conhecido e utilizado na medicina, sua definição segundo o dicionário Aurélio traz: ramo da medicina que se dedica ao estudo das doenças, de suas causas, sintomas e suas alterações no organismo. Analogamente, as patologias das construções estudam as doenças, causas e sintomas das alterações das funções e comportamento das edificações.

EdifIcações centenárias são propícias a apresentar Manifestações Patológicas (MP), devido ao surgimento de variados problemas ao decorrer dos anos. Segundo Santos; Costa e Silva (2017), as construções de casarões se intensificaram a partir da segunda metade do século XVIII, surgidos com a ascensão da burguesia Portuguesa nas cidades de Recife e Olinda, e muitos desses casarões resistem até os dias atuais e contribuem para o acervo histórico e cultural das cidades. Entretanto, muitos desses patrimônios históricos precisam ser reparados rotineiramente e periodicamente, pois a presença de manifestações patológicas é muito comum, tendo que dispensar cuidados especiais a fim de evitar problemas mais sérios que causariam até o colapso da estrutura.

Esse trabalho, visa apresentar investigação das principais MP encontradas na alvenaria do prédio do bloco A, da Escola Politécnica de Pernambuco, atribuindo um levantamento de subsídios, às principais causas e os devidos mecanismos para a resolução dos inconvenientes encontrados na edificação. Para isso foi necessário seguir a metodologia utilizada para avaliação de MP, que são: levantamento de subsídios, diagnóstico da situação, definição de conduta, avaliação com o registro do caso e o programa de manutenção preventiva.

\section{REFERENCIAL TEÓRICO}

Nessa etapa do trabalho, serão conceituadas as manifestações patológicas ocorridas em patrimônio históricos, bem como, a anamnese, através de um breve histórico da edificação, descrita pela literatura.

\subsection{Patrimônio histórico}

Considerado como a união de bens gerados ao longo dos anos por uma determinada nação, o patrimônio histórico, apresenta os traços econômicos, arquitetônicos e culturais, remetendo, desta forma uma imagem de uma propriedade adquirida e inserida nos costumes dos habitantes da localidade. Através da preservação desses bens é possível preservar a memória da cidade mantendo traços de costumes, cotidiano e da vida do grupo social residente em períodos passados, apresentando um alto valor para a personalidade histórica da cidade (TOMAZ, 2010). A inclusão do patrimônio cultural torna-se indispensável em meio à malha urbana pós-moderna, desse modo, visando a conservação, as recuperações dos patrimônios ocorrem de forma a manter a tipologia arquitetônica da edificação, garantindo sua identidade, formato e cor (DELAVAUD, 2008).

O Instituto do Patrimônio Histórico e Artístico Nacional (IPHAN) é o órgão responsável pela conservação de edificações históricas no Brasil. As restaurações feitas por esse órgão, podem ser inovadoras e/ ou conservativas porém normalmente são feitas para preservar a identidade do imóvel (CUNHA, 2010).

\subsection{Breve histórico}

A Escola Politécnica de Pernambuco - POLI, foi idealizada por estudiosos que enfrentaram diversas dificuldades da época em que a cidade de Recife ainda não dispunha de escola de engenharia. Com data de criação em 1912, o marco de suas atividades acontecem em janeiro de 1913. De lá para cá, a POLI só tem contribuído positivamente na formação de profissionais capacitados e de destaque nacional. Em 1937 a Escola Politécnica se instala na Casa do Benfica e em 1952, une-se a Universidade Católica de Pernambuco e consegue o reconhecimento da mesma junto ao Ministério da Educação - MEC e depois, já difundida da Universidade Católica em 1990 é fundada a Universidade de Pernambuco e recebe de fato seu reconhecimento do MEC.

As atividades da Escola Politécnica desde que realizada em prédio próprio, acontecem no mesmo endereço até a atualidade. Suas atividades iniciaram na então conhecida casa do Benfica. Um casarão com dois pavimentos, todo em alvenaria, com aspectos arquitetônicos da época (DOS SANTOS, 1991). 
Em 1959, após 22 anos de ocupação do prédio, houve uma reforma necessária, porém, o projeto lamentavelmente não preservou as elegantes linhas coloniais da casa, entretanto, adaptou o espaço as exigências de uma Escola, na época. Segundo o que relata Dos Santos (1991), foram realizados reparos de substituição da escada de madeira nobre por outra construída em concreto armado, revestida de mármore, ostentando um bonito corrimão de ferro e bronze, adornado com peças douradas. Além disso, foram feitas mudança na cobertura, substituição dos lustres de cristal por luminárias fluorescentes, alteração da divisão interna, mudança dos pisos de madeira para granito tudo feito com fino acabamento, etc. Em 1984, houve um acidente na Escola: o desabamento de parte do teto do Bloco A, provocando sua interdição. Em nova restauração o madeiramento do teto foi substituído por estrutura metálica, o mesmo encontrava-se deteriorado pela ação do cupim, além de terem sido processadas reformas nas divisões internas, instalando um pequeno auditório climatizado, com capacidade para cem pessoas, duas salas de aula para quarenta alunos cada, e um salão projetado para, receber o Núcleo de Informática da Politécnica — NIP, àquela época.

\subsection{Inspeções em edificações}

Para (LISBOA et al., 2018) determinados fatores podem aumentar o tempo do ciclo de vida útil das edificações, um dos mais relevantes a considerar é, o meio em que a edificação está inserida, manutenção de edificações é item essencial, porém é necessário dar importância aos processos construtivos para evitar reparações desnecessárias.

O diagnóstico de MP deve ser realizado a partir de uma inspeção visual coletando dados e identificando todos os sintomas observados, principalmente anotando sua localização e intensidade, geralmente um conjunto de fatores estão relacionados ao surgimento de problemas patológicos em edificações, desencadeando em anomalias. Para atingir a vida útil de projeto é necessário promover manutenções preventivas periódicas com acompanhamento e cumprimento do planejamento previsto no programa de manutenção desenvolvido na fase de concepção do projeto. De acordo com a ABNT NBR 15575:2013, as edificações devem ter desempenho mínimo de operação por 50 anos, já o tempo de concepção de inúmeros empreendimentos são relativamente curto, o que pode ocasionar ineficiência de projetos (TUTIKIAN; PACHECO, 2013).

Durante as inspeções em edificações o ideal é realizar o mínimo de interferência possível, evitando interdições sejam ela parciais ou totais, assim o aperfeiçoamento de técnicas e ajuda da tecnologia é possível agregar agilidade nessa progressiva necessidade de inspecionar. A utilização de veículo aéreo não tripulado na construção civil ainda é restrita, porém possui amplo potencial como método não destrutivo na inspeção e detecção de MP principalmente em fachadas, podendo ser analisado variados tipos de MP, a exemplo: eflorescência, desplacamento, manchas, fissuras entre outras. (LISBOA et al., 2018).

\subsubsection{Principais tipos de manifestações patológicas em alvenaria}

Os avanços da construção civil no Brasil, em seus últimos anos preocupa, pois, desenvolvimento tecnológico na utilização de materiais, faz com que se utilize estruturas esbeltas, atendam prazos desafiadores e isso evidenciando a observação de manifestações patológicas recorrentes (LORDSLEEM et al., 2016).

Segundo (LORDSLEEM JR., 2019; MORAIS; LORDSLEEM JR, 2019), as manifestações mais frequentes encontradas nas alvenarias são: umidade, bolor, eflorescências, trincas/ fissuras.

A umidade é decorrente do estado úmido do solo ou dos materiais expostos à água, umidade do ar e direção dos ventos. Além disso, é um dos fatores determinantes para a manifestação de bolor nas alvenarias de vedação, o qual são microrganismos (fungos) que se desenvolvem a partir do alto teor de umidade. Já a eflorescência é produzida pela água com sódio e potássio, quando o líquido evapora sobra apenas no depósito salino nas superfícies provocando manchas (KLEIN, 1999; ALUCCI; FLAUZINO; MILANO, 1985; UEMOTO, 1985 apud SOUZA, 2008).

As fissuras atingem apenas a camada superficial dos materiais, dificilmente excedendo a espessura de $1 \mathrm{~mm}$. A causa resultante é a necessidade da diminuição das tensões exercidas levando ao rompimento. Entretanto, as trincas são manifestações patológicas com espessura de ruptura maior, originadas por problemas estruturais, exemplificando (SABBATINI, 1984 apud LORDSLEEM, 1997).

\subsubsection{Principais origens e causas das manifestações patológicas em alvenaria}


Desenvolver um sistema de inspeção e diagnóstico é pertinente e elementar para conhecer a causa da manifestação patológica, isso indica a utilização da intervenção corretiva adequada nas paredes de alvenaria, impedindo assim o seu agravamento pois, características climáticas e geográficas do país onde a edificação está construída influência na abordagem sistemática para inspeção de paredes de alvenaria. Alguns elementos da parede podem influenciar na durabilidade e desempenho da mesma, tais como materiais de isolamento e sistema de ancoragens que são utilizados para interligar as paredes aos elementos estruturais e outros elementos como esquadrias, ou até mesmo diferentes tipos de alvenarias. (GONÇALVES; DE BRITO; AMARO, 2015).

\section{METODOLOGIA}

A metodologia adotada para a consecução desta pesquisa contemplou as seguintes fases, ilustradas na Figura 1:

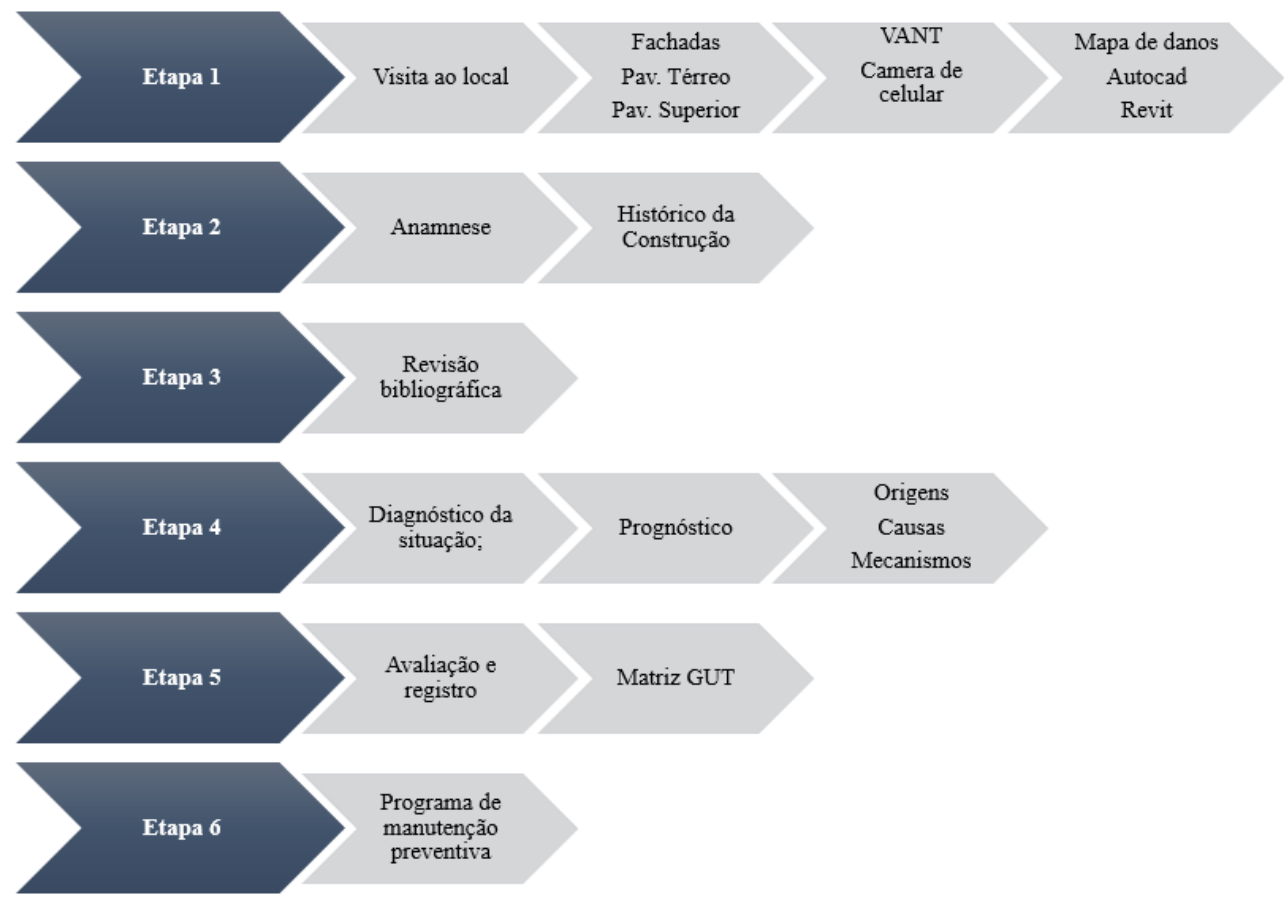

Figura 1 - Etapas da metodologia proposta

As seguintes etapas pertinentes às fases citadas são descritas:

- $\quad$ Etapa 1 - visita ao local: foram feitas visitas periódicas ao local, com a finalidade de mapear as MP na alvenaria do prédio e fazer medições para a confecção do projeto arquitetônico atualizado utilizando o software da Autodesk Revit ${ }^{\circledR}$ 2019. Inicialmente, foram verificadas as fachadas do prédio por meio de Veículo Aéreo Não Tripulado (VANT), modelo PHANTOM 4 Pro V2.0, acoplado de câmera fotográfica de alta resolução. Nas demais visitas, foram analisados o interior do prédio nos dois pavimentos (pavimento térreo e superior), registrando por meio de fotos as MP encontradas na alvenaria. Como também, realizando medições com trena magnética a laser da marca FLUREON e trena metálica com alcance de $60 \mathrm{~m}$ e $5 \mathrm{~m}$ respectivamente.

- $\quad$ Etapa 2 - anamnese: foram levantadas informações acerca da construção do casarão, para embasamento técnico dos materiais utilizados, tempo de construção, forma de utilização, execução de reformas e manutenções ao longo do funcionamento.

- $\quad$ Etapa 3 - revisão bibliográfica: investigação dos principais conceitos na literatura disponíveis em livros, artigos, periódicos, dissertações, teses e normas técnicas. Estabelecendo os parâmetros para os resultados obtidos no estudo de caso. 
- $\quad$ Etapa 4 - diagnóstico da situação: com as verificações realizadas in loco, identificou-se as supostas origens e causas das manifestações patológicas na alvenaria do casarão..

- $\quad$ Etapa 5 - avaliação e registro: apresentaram-se mecanismos que poderão ser utilizados para a correção das MP, avaliados por meio da matriz GUT (Gravidade, Urgência e Tendência) como prognóstico para a tomada de decisões na realização dos reparos a serem executados.

- $\quad$ Etapa 6 - programa de manutenção preventiva: propor um programa preventivo descrevendo os cuidados necessários e periodicidade relacionados às MP nas alvenarias que poderão surgir ao longo dos próximos anos.

\section{4. ÁREA DE ESTUDO}

Atualmente a Escola Politécnica de Pernambuco está localizada no mesmo endereço: Rua Benfica, 455 bairro da Madalena em Recife - Pernambuco, funcionando com 9 blocos que são listados de A-H, resultando-se em uma área construída de $9.231,59 \mathrm{~m}^{2}$, que abrigam, dentre eles, salas de aulas para graduação e pós-graduação (latu sensu e stricto sensu), salas administrativas, laboratórios e espaços de convivência, conforme pode ser visualizado na Figura 2. O objeto de estudo foi realizado no Bloco A (em destaque na Figura 2), único prédio considerado histórico dentro das dependências da Universidade e o sistema construtivo foi feito de alvenaria com tijolos maciços e uma parte de blocos cerâmicos, a escada do prédio foi reformada e feita de concreto armado, sendo sua arquitetura inspirada em construções do século XVIII.

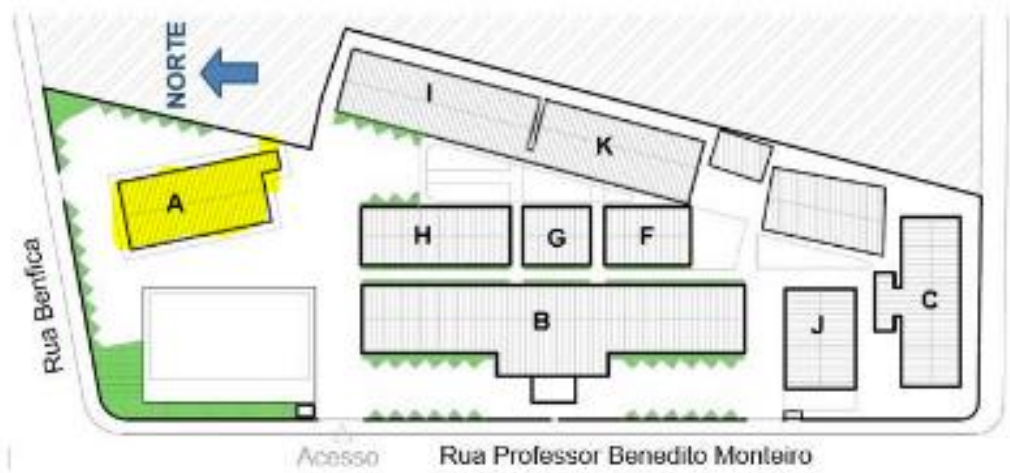

Figura 2: Blocos da Escola Politécnica da Universidade de Pernambuco, em destaque está o objeto de estudo da pesquisa.

\section{RESULTADOS E DISCUSSÕES}

\subsection{Etapa 1: Visita ao local}

\subsubsection{Uso do VANT para reconhecimento das manifestações patológicas nas fachadas}

Para o reconhecimento das manifestações patológicas nas fachadas utilizou-se um VANT, identificando algumas MPs ocorridas principalmente nas partes superiores das alvenarias e proximidades do telhado. Com a qualidade dessas imagens pode-se analisar com muita clareza os tipos de MP em locais de difícil acesso. Como pode ser visto Quadro 1. 


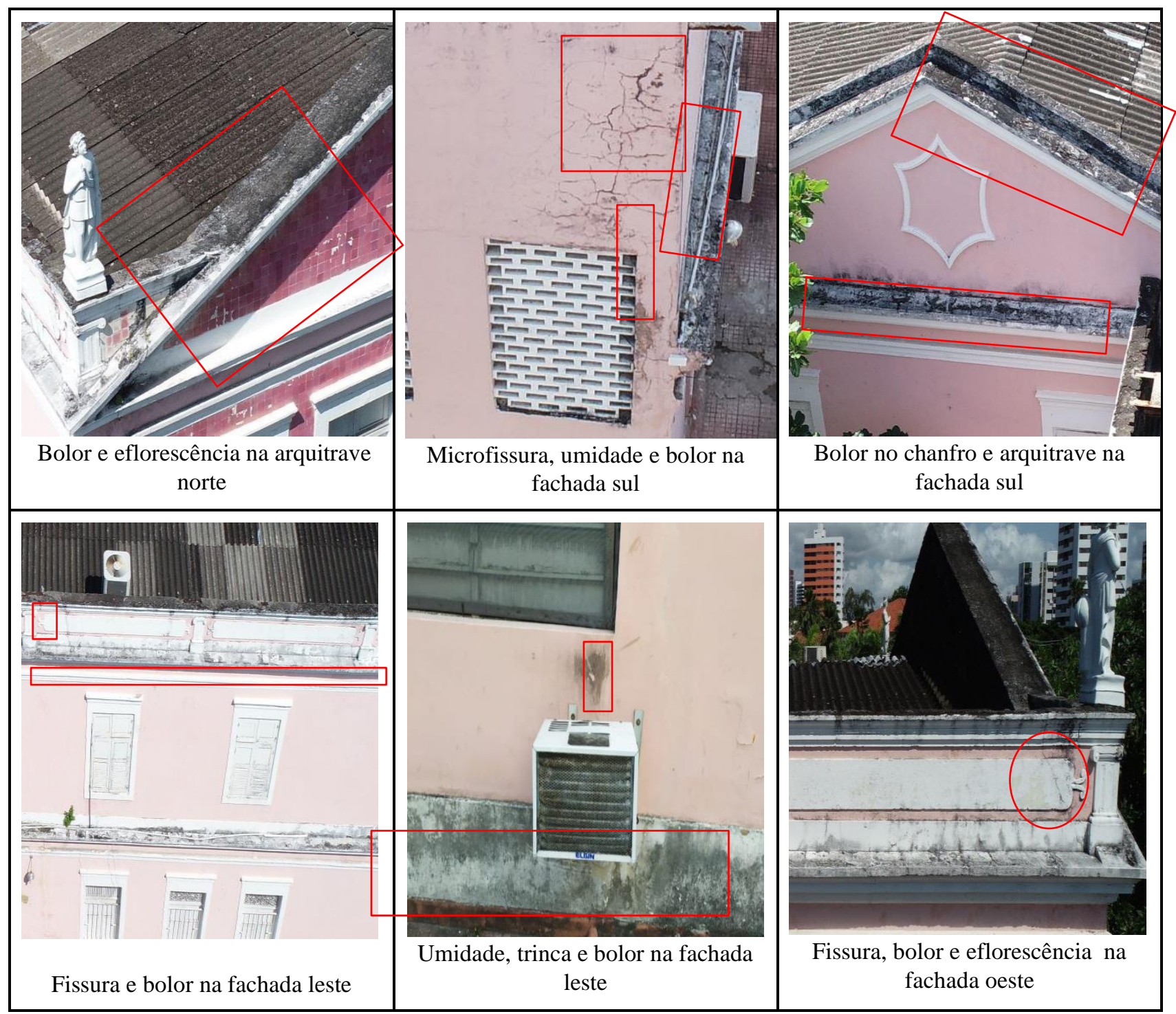

Quadro 1: Principais MP encontradas nas fachadas.

\subsubsection{Visita ao interior do edifício}

No interior do edifício, iniciando-se com o térreo percebeu que a sala que apresentou mais problemas foi o laboratório de informática, conhecido como LIP 4, podendo ser visualizado as principais manifestações no Quadro 2. 


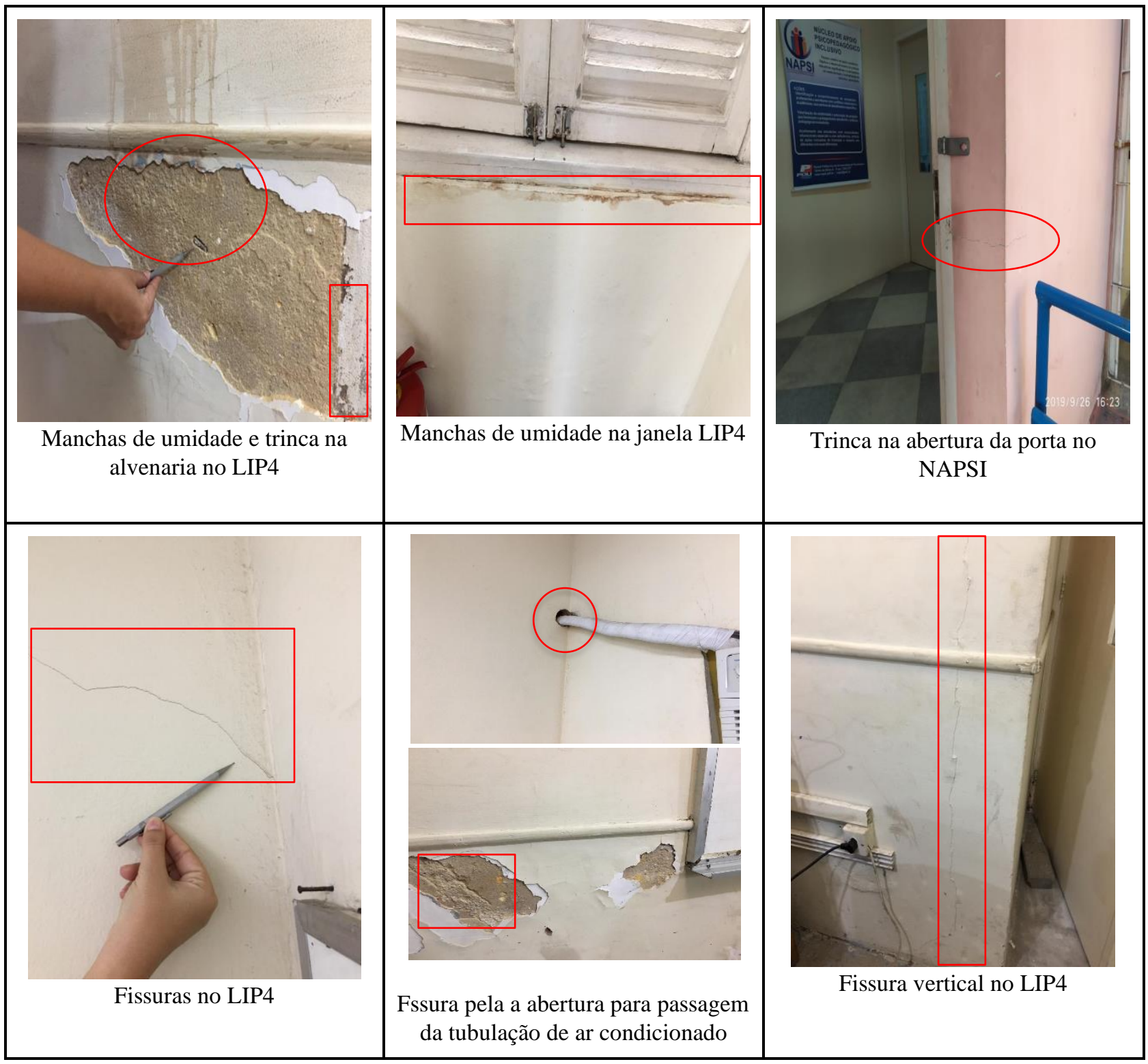

Quadro 2: Principais MP encontradas no pavimento térreo

No piso superior, encontra-se o auditório, foyer, salas de apoio e escada de emergência, onde através de inspeção visual, na sala de apoio e nas proximidades da escada de emergência, percebeu-se que eram lugares que apresentaram uma maior preocupação, como pode ser visto no Quadro 3. 


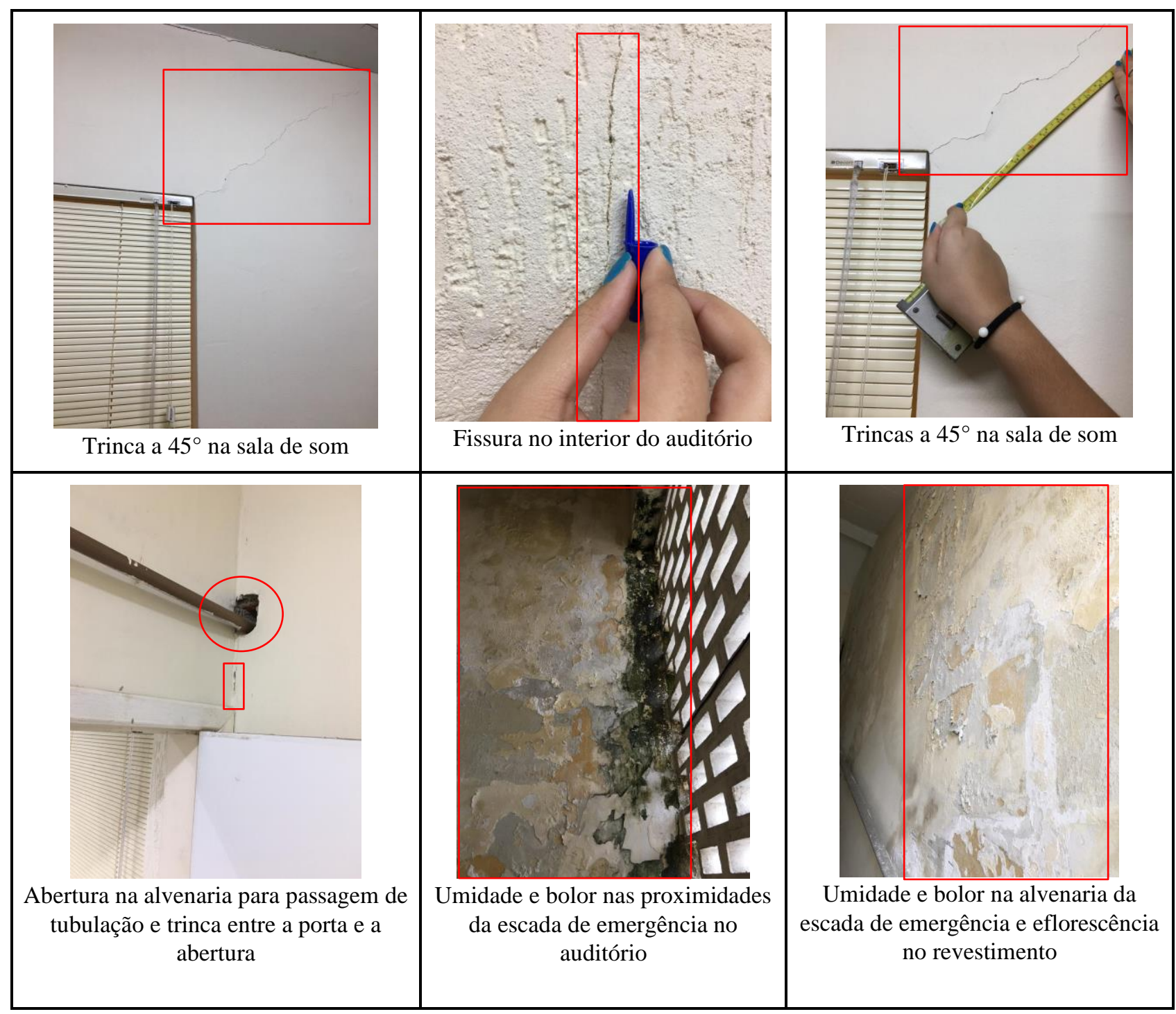

Quadro 3: Principais manifestações patológicas na alvenaria do pavimento superior

\subsubsection{Mapa de danos das fachadas}

A partir do levantamento fotográfico, foram identificadas os locais das principais manifestações patológicas encontradas na alvenaria da edificação, após, foram desenhados os mapas de danos das 4 fachadas, utilizando-se do software Autodesk Autocad 2019. Os principais tipos de MP encontradas, podem ser visualizadas na Figura 3 que possui o quadro de legenda.

\section{LEGENDA - MAPA DE DANOS \\ PRINCIPAIS PROBLEMAS PATOLOGICOS \\ FISSURAS E TRINCAS \\ $\square$ EFLORESCENCIAS \\ $\square$ BOLOR \\ UMIDADE}

Figura 3: Legenda das principais manifestações patológicas nas fachadas.

$\mathrm{Na}$ fachada norte, a principal MP na alvenaria identificada foi o bolor, que esteve presente em toda arquitrave e na base do pilar superior esquerdo, conforme pode ser visualizado na Figura 4a. Vale ressaltar que haviam outras patologias na 
fachada norte, porém com origem no revestimento, não sendo catalogadas por não fazer parte do objetivo deste trabalho. $\mathrm{Na}$ fachada sul (Figura 4b.), percebeu-se uma maior incidência de bolor e umidade ao longo de toda a base da edificação e na arquitrave; fissuras/trincas nas proximidades das portas e cobogôs.

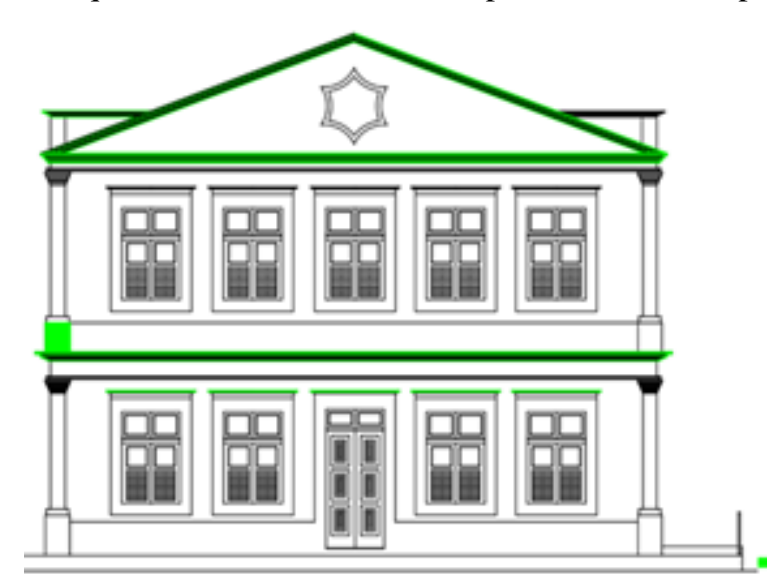

a) Fachada Norte

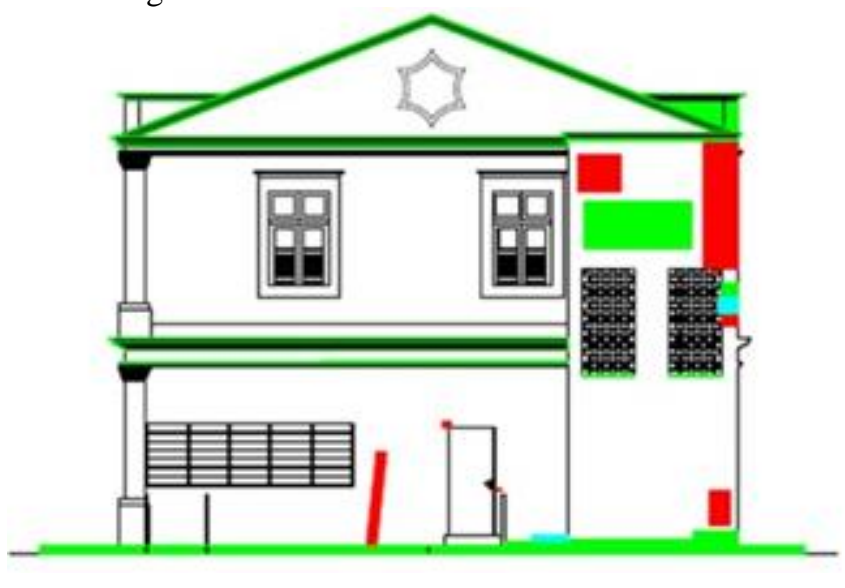

b) Fachada Sul

Figura 4: Fachadas principais do edifício

Na fachada oeste (Figura 5) e leste (Figura 6), foram encontradas as quatro principais MP nas alvenarias, sendo a maior incidência de bolor, eflorescências, fissuras/trincas e umidade respectivamente.

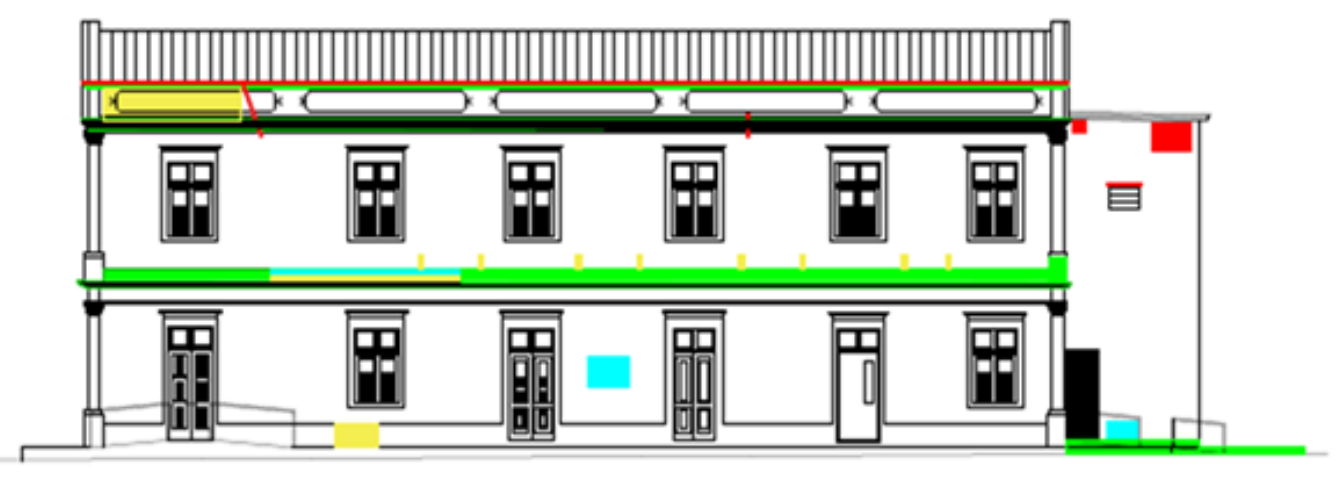

Figura 5: Fachada Oeste

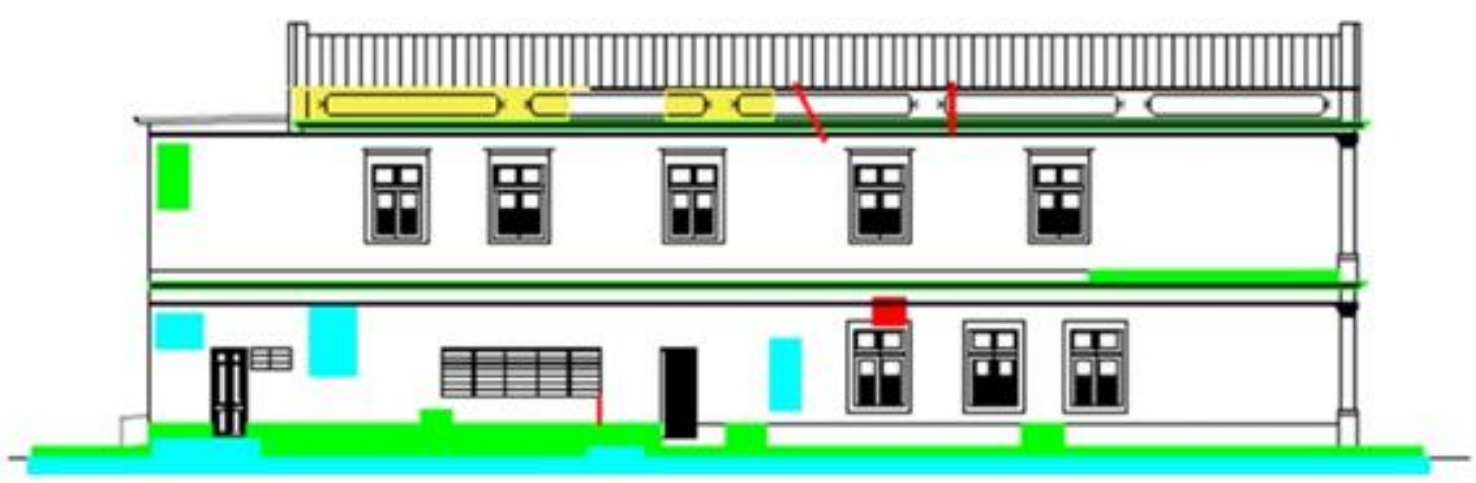

Figura 6: Fachada Leste 


\subsubsection{Pavimento Térreo}

Após as medições, foram feitas atualizações das plantas existentes, e modeladas usando o Autodesk Revit 2019, planta baixa do pavimento térreo, superior e a modelagem da fachada, mostrando-se a localização das MP encontradas in loco. O pavimento térreo encontrava-se livre de MP em dois ambientes, sala da secretaria do PEC e HALL de acesso ao auditório do pavimento superior, devido a reformas recentes nesses ambientes. Nos demais ambientes foi identificado presença principalmente de fissura/trinca, umidade e bolor, conforme visualizado na Figura 7.

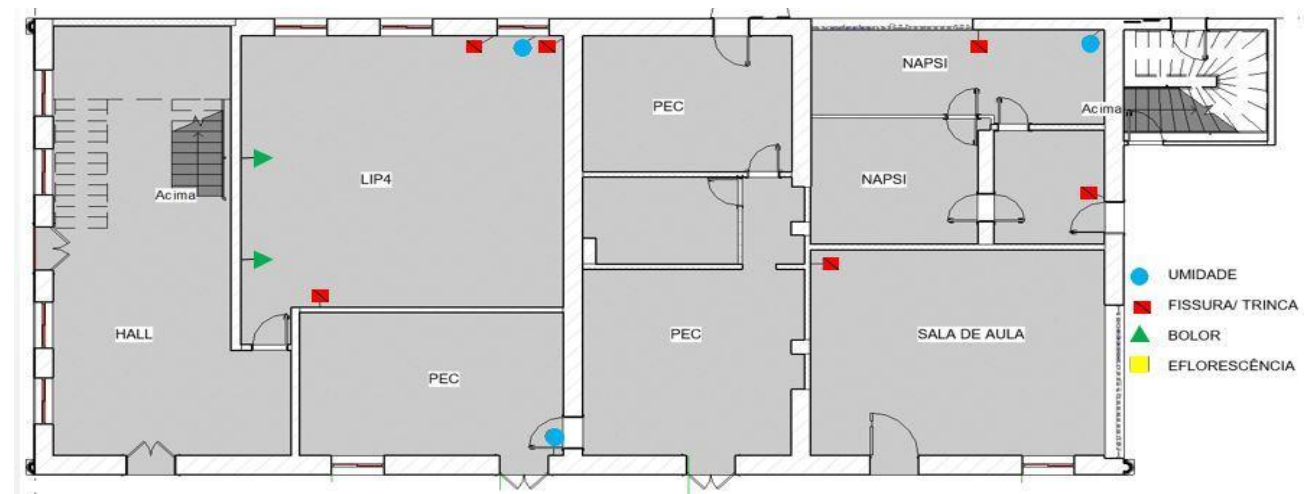

Figura 7: Pavimento Térreo

\subsubsection{Pavimento Superior}

O pavimento superior é praticamente composto pelo auditório, apresentando fissuras/trincas como a principal MP, principalmente nas salas de apoio. A escada de emergência foi a área mais crítica, percebendo-se a presença de umidade e bolor, conforme pode ser analisado na Figura 8.

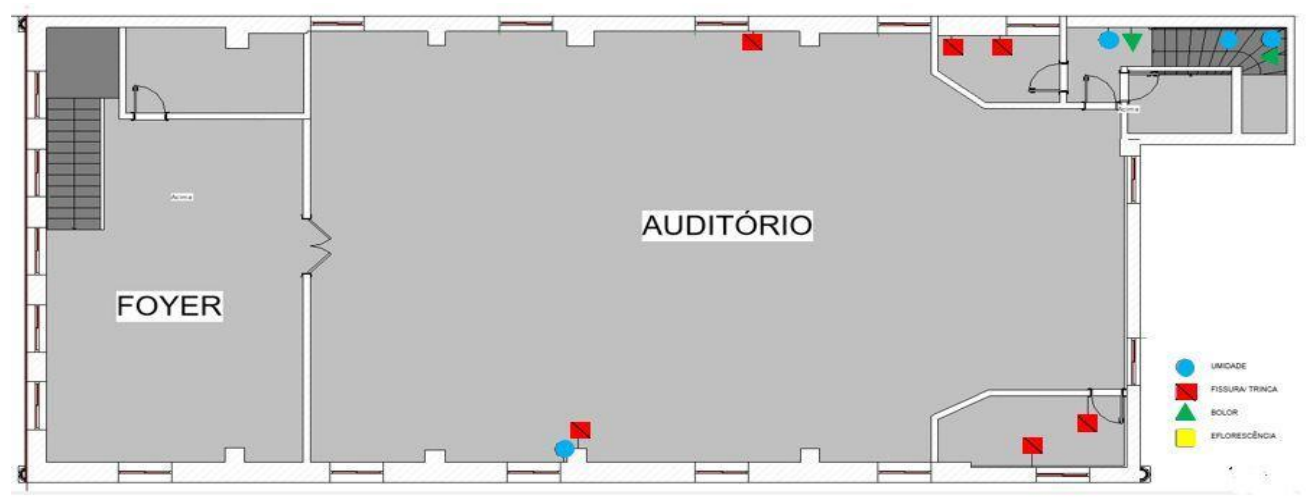

Figura 8:Pavimento Superior

\subsubsection{Modelação do edifício em 3D}

A modelagem (Figura 9), não se deve apenas a vista 3D, mas também por ser possível realizar uma modelação paramétrica do edifício, podendo assim fazer um projeto com informações reais sobre a constituição dos materiais da edificação, no sentido de inseri-las e se ter um banco de dados, facilitando em caso de reforma e manutenções preventivas. 


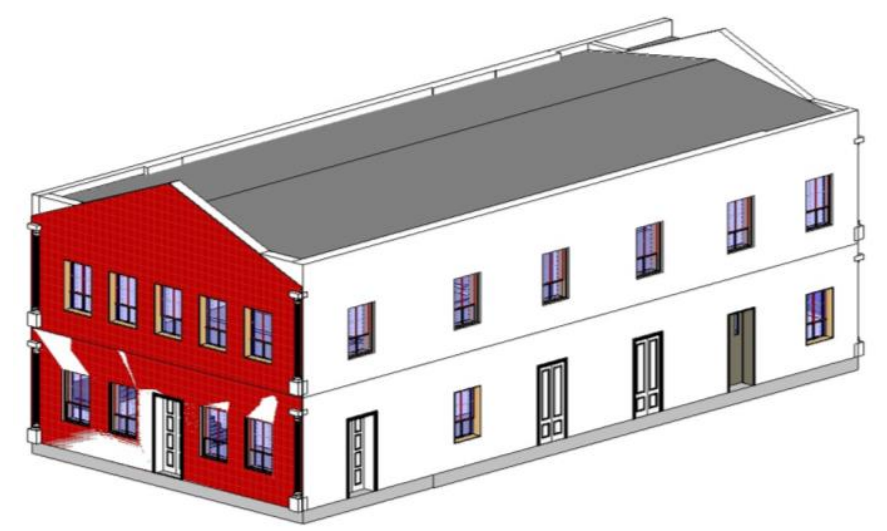

Figura 9: Modelagem em 3D da edificação

\subsection{Etapa 4: Origens e Causas}

As supostas origens que levaram o surgimento das MP são adquiridas com o passar do tempo, visto que o prédio estudado é centenário, tendo passado do seu tempo de vida útil. As causas das fissuras a $45^{\circ}$ encontradas principalmente nas janelas e portas, podem ser devido a ausência de vergas e contravergas. Com relação às causas, pode-se enumerar as principais causas das MP no Quadro 4.

\begin{tabular}{l|l}
\hline Manifestação Patológica & \multicolumn{1}{c}{ Causa } \\
\hline Bolor & Climas considerados úmidos e presença de umidade. \\
\hline Eflorescência & Lixiviação do $\mathrm{Ca}(\mathrm{OH}) 2$ carregado pela infiltração de água e cura inadequada. \\
\hline Fissuras/Trincas & Movimentações térmica, fundações ou higroscópica \\
\hline Umidade & Intempéries e teor de umidade relacionados ao clima da cidade ou vazamentos \\
\hline
\end{tabular}

Quadro 4 - Principais causas das manifestações encontradas

\subsection{Etapa 5: Análise de tomada de decisão}

\subsubsection{Matriz GUT}

Para a análise de tomada de decisão, inicialmente foram listados os tipos de MP na alvenaria e atribuídos uma escala de urgência de 1-5, onde quanto maior o número, maior a gravidade e urgência do tipo de MP. Para isso foi utilizado a matriz GUT, conforme apresentado na Tabela 1, onde os autores por meio das visitas in loco identificaram que dentre as MP apresentadas as que tiveram a maior urgência em fazer as medidas corretivas estão descritas na seguinte ordem: umidade, trincas, fissuras, eflorescência e bolor.

Tabela 1 - Tabela GUT de análise de tomada de decisão

\begin{tabular}{c|c|c|c|c}
\hline \multirow{2}{*}{ Problemas } & $\begin{array}{c}\text { G } \\
\text { Gravidade }\end{array}$ & $\begin{array}{c}\text { U } \\
\text { Urgência }\end{array}$ & $\begin{array}{c}\text { T } \\
\text { Tendência }\end{array}$ & GUT \\
\hline Bolor & 2 & 1 & 3 & 6 \\
\hline Eflorescência & 2 & 1 & 3 & 6 \\
\hline Fissura à $45^{\circ}$ & 3 & 2 & 4 & 24 \\
\hline
\end{tabular}




\begin{tabular}{c|c|c|c|c}
\hline Fissuras & 3 & 2 & 4 & 24 \\
\hline Trincas & 4 & 2 & 4 & 32 \\
\hline Umidade & 5 & 3 & 5 & 75 \\
\hline
\end{tabular}

\subsubsection{Mecanismos}

- Umidade: na edificação foram encontradas predominantemente umidades provenientes do solo, e este tipo de umidade deve ser reparada com o uso de impermeabilizantes na base do edifício. Em alguns casos, percebeu umidade na alvenaria da fachada devido a aberturas que não foram fechadas de tubulação para condicionadores de ar, e dessa maneira a água está passando e infiltrando na alvenaria. Para as arquitraves é necessário que se deixe uma pequena inclinação, para que em tempos chuvosos a água possa escoar, impedindo que a mesma não se acumule e infiltre na alvenaria. As umidades aparentes nas paredes da escada de emergência, é necessário escarificar a superfície e analisar de onde vem a água que está fazendo com que se tenha bolores e eflorescência, no segundo momento inserir os aditivos impermeabilizantes ao chapisco e fazer a aplicação na parede. Na aplicação da argamassa também são adicionados os aditivos impermeabilizantes e por fim a pintura (FIBERSALS, 2018).

- Fissuras/ trincas: nas fissuras encontradas, pode ser feito uso de sistemas flexíveis ou sistemas rígidos em algumas trincas no caso da trinca a $45^{\circ}$, pode ser usado a técnica de grampeamento ou armadura horizontal.. Nas fissuras encontradas dentro da edificação, pode ser utilizado sistemas flexíveis, como por exemplo: o sistema POLI, no qual se deve retirar o revestimento, passar uma demão de selador, fixação da fita, colocar massa de recuperação, após utilizar o véu de poliéster, mais uma camada de massa de recuperação, (repetir os dois passos anteriores), aplicar uma camada de massa de acabamento, lixar e pintar. A estrutura encontra-se estável, e em pleno funcionamento e ocupação.

- Eflorescência: O processo para eliminação no primeiro momento deve-se ser lixado para a eliminação das áreas manchadas acometidas pelo excesso de salinização. Com intuito de proteger a parede da edificação é recomendado a aplicação de fundos preparadores de paredes, e após aguardado o tempo de secagem efetuar a pintura.

- Bolor: O bolor é composto por microorganismos instalados nas superfícies e a sua proliferação é condizente a climas considerados úmidos e presença de umidade na parede. Sendo o Recife composto por um clima úmido é totalmente propenso para o desenvolvimento desses microorganismos. Certo disso, se faz necessário tratar primeiramente os problemas de umidade e após fazer a eliminação do bolor, tem que se aplicar mistura com cloro e água para a retirada do bolor existente, e após fazer a aplicação de produtos fungicidas. Para evitar problemas futuros é preciso estabelecer um programa de manutenção por motivos da exposição ao clima úmido da cidade do Recife.

\subsection{Etapa 6: Programa de manutenção preventiva em alvenaria do bloco A}

Um programa de manutenção deve se embasar nas responsabilidades impostas pela ABNT NBR 14037 e ABNT NBR 5674, e então definição do grupo de atividades a serem realizadas, definindo periodicidade, profissionais responsáveis e necessidades de recursos para serem realizadas. No que tange a manutenção em alvenaria de vedação do prédio em estudo, as ações estão descritas no Quadro 5:

\begin{tabular}{c|c|c|c|c|c}
\hline Período & Sistema & $\begin{array}{c}\text { Elemento/ } \\
\text { Componente }\end{array}$ & Atividade & Observações & Responsável \\
\hline $\begin{array}{c}\text { A cada 2 } \\
\text { anos }\end{array}$ & $\begin{array}{c}\text { Alvenaria } \\
\text { em tijolos } \\
\text { maciços }\end{array}$ & $\begin{array}{c}\text { Paredes em tijolo } \\
\text { maciços dos } \\
\text { ambientes } \\
\text { internos e } \\
\text { externos }\end{array}$ & $\begin{array}{c}\text { Inspeção visual praticada } \\
\text { por profissional/ empresa } \\
\text { habilitada tecnicamente, } \\
\text { realizar levantamento e } \\
\text { produzir documento da } \\
\text { anomalia encontrada: } \\
\text { tipo, causa, origem, } \\
\text { tratamento. }\end{array}$ & $\begin{array}{c}\text { Após inspeção da } \\
\text { integridade das paredes } \\
\text { de alvenaria, acompanhar } \\
\text { serviços a serem } \\
\text { realizados produzindo } \\
\text { relatórios e observando a } \\
\text { utilização dos } \\
\text { instrumentos necessários } \\
\text { para o resultado esperado. }\end{array}$ & $\begin{array}{c}\text { Manuipe de } \\
\text { Institucional }\end{array}$ \\
\hline
\end{tabular}




\begin{tabular}{|c|c|c|c|c|c|}
\hline $\begin{array}{c}\text { A cada } 2 \\
\text { anos }\end{array}$ & $\begin{array}{l}\text { Alvenaria } \\
\text { em bloco }\end{array}$ & $\begin{array}{c}\text { Paredes em } \\
\text { blocos cerâmicos } \\
\text { dos ambientes } \\
\text { internos. }\end{array}$ & $\begin{array}{l}\text { Inspeção visual praticada } \\
\text { por profissional ou } \\
\text { empresa habilitada } \\
\text { tecnicamente, realizar } \\
\text { levantamento e produzir } \\
\text { documento da anomalia } \\
\text { encontrada: tipo, causa, } \\
\text { origem, tratamento }\end{array}$ & $\begin{array}{l}\text { Documentar os locais que } \\
\text { passaram por manutenção } \\
\text { descrevendo todos os } \\
\text { serviços realizados. }\end{array}$ & $\begin{array}{l}\text { Equipe de } \\
\text { Manutenção } \\
\text { Institucional }\end{array}$ \\
\hline $\begin{array}{c}\text { A cada } 1 \\
\text { ano }\end{array}$ & Divisórias & $\begin{array}{l}\text { Divisórias em } \\
\text { gesso de } \\
\text { ambientes } \\
\text { internos. }\end{array}$ & $\begin{array}{l}\text { Inspecionar a integridade } \\
\text { das divisórias de gesso. }\end{array}$ & $\begin{array}{l}\text { Em caso de detectar } \\
\text { anomalias, solicitar } \\
\text { manutenção corretiva } \\
\text { imediatamente. }\end{array}$ & $\begin{array}{c}\text { Equipe de } \\
\text { Manutenção } \\
\text { Institucional }\end{array}$ \\
\hline $\begin{array}{c}\text { A cada } 1 \\
\text { ano }\end{array}$ & Arquitrave & $\begin{array}{l}\text { Elemento } \\
\text { arquitetônico } \\
\text { presente em todas } \\
\text { as fachadas. }\end{array}$ & $\begin{array}{c}\text { Inspeção visual técnica } \\
\text { identificando surgimento } \\
\text { de possíveis MP }\end{array}$ & $\begin{array}{l}\text { Na ocorrência de MP, } \\
\text { solicitar manutenção } \\
\text { corretiva imediatamente. }\end{array}$ & $\begin{array}{l}\text { Equipe de } \\
\text { Manutenção } \\
\text { Institucional }\end{array}$ \\
\hline
\end{tabular}

Quadro 5 - Programa de manutenção

\section{CONCLUSÕES}

Percebe-se a importância de se ter programas de manutenção nas edificações, pois com o decorrer dos anos as edificações necessitam ser reparadas e as manutenções preventivas são mais vantajosas, por serem menos onerosa e não comprometer tanto o funcionamento do prédio. Na edificação em estudo as MPs encontradas estão causando danos estético à construção, entretanto recomenda-se os reparos para evitar a evolução que pode vir a comprometer a estrutura da edificação, visto que se trata de um prédio centenário.

Com o propósito de impossibilitar maiores danos ao prédio, sendo danos funcionais ou até mesmo comprometendo a estrutura, será necessário a realização de medidas corretivas em todo o conjunto voltando atenção aos locais mais críticos que foram: fachadas, escada emergência e sala de aula LIP 4. Após recomenda-se que se faça um programa de manutenção preventiva, conforme o que foi estabelecido e procure-se ter periodicamente esse acompanhamento por profissionais devidamente habilitados.

\section{AGRADECIMENTOS}

Agradecemos a todos os colobarodores da pesquisa, ao Professor Dr. Alberto Casado por permitir em sua disciplina desenvolver esse trabalho, ao PEC (Programa de Pós-graduação em Engenharia Civil) e a POLI/UPE, por ter desenvolvidos linhas de pesquisas e formado mestres com excelência nos últimos anos. A CAPES por ser o orgão de fomento do autor principal.

\section{REFERÊNCIAS}

ASSOCIAÇÃO BRASILEIRA DE NORMAS TÉCNICAS. NBR 5674: Manutenção de Edificações - Requisitos para o sistema de gestão e manutenção. Rio de Janeiro, 2012.

ASSOCIAÇÃO BRASILEIRA DE NORMAS TÉCNICAS. NBR 14037: Diretrizes para elaboração de manuais de uso, operação e manutenção das edificações - Requisitos para elaboração e apresentação dos conteúdos. Rio de Janeiro, 2014. 
CUNHA, C. dos R. Restauração: diálogos entre teoria e prática no Brasil nas experiências do IPHAN. 171p. Tese (Doutorado). Faculdade de arquitetura e urbanismo da universidade de São Paulo. 2010.

DELAVAUD, A. C. ¿Aparición de una nueva cultura patrimonial en américa latina a través de los centros históricos en "re-construcción"? Investigación y desarrollo. Caribe, v. 16, n.1, p. 32-57, 2008.

DOS SANTOS, M. H. R. Escola Polytechnica de Pernambuco 1911 -1991. Companhia Editora de Pernambuco, $1^{\circ}$ ed. 75 f. 1991.

FIBERSALS. Impermeabilização em paredes: como fazer para acabar com a infiltração [2018]. Disponível em: https://fibersals.com.br/blog/impermeabilizacao-em-paredes-como-fazer/. Acesso em: 9 nov. 2019.

GONÇALVES, A.; BRITO, J.; AMARO, B. Systematic Approach to Inspect, Diagnose, and Repair Masonry Walls. Journal of Performance of Constructed Facilities, v. 29, n. 6, p. 1-12, 2015.

LISBOA, D. W. B. L. et al. Utilização do VANT na inspeção de manifestações patológicas. In: Congresso Técnico Científico da Engenharia e da Agronomia. Maceió - AL: Brasil, 2018. p. 1-5.

LORDSLEEM JR., A.C. Manifestações patológicas das alvenarias de vedação. In: Alberto Casado Lordsleem Júnior; Alexandre Duarte Gusmão. (Org.). Patologia das construções dos edifícios. 1ed.Recife: EDUPE, 2018, v. 1, p. 77-104.

LORDSLEEM JR., A.C. Sistemas de recuperação de fissuras da alvenaria de vedação: avaliação da capacidade de deformação. 2002. 195p. Dissertação (Mestrado). Escola politécnica da universidade de São Paulo. 1997.

LORDSLEEM JR., A. C. et al. Case Studies of Building Pathology in Cultural Heritage. [S.1: s.n.], 2016. v. 7 . . Disponível em: http://link.springer.com/10.1007/978-981-10-0639-5. Acesso em: 16 out. 2019.

LORDSLEEM JR., A.C. Sistemas de recuperação de fissuras da alvenaria de vedação: avaliação da capacidade de deformação. 2002. 192 p. Dissertação (Mestrado). Escola politécnica da universidade de São Paulo. 1997.

MORAIS, G. A. T.; LORDSLEEM JR., A. C. Building maintenance management activities in a public institution. Engineering, Construction and Architectural Management. v. 26, n. 1, p. 85-103, 2019.

SANTOS, C. L. L.; COSTA e SILVA, A. J. Conservação de edifício histórico do Século XIX - Análise de Patologias na Fachada do Bloco A da Escola Politécnica da Universidade de Pernambuco. In. Conferência Nacional de Patologia e Recuperação de Estruturas - CONPAR, 2017.

SOUZA, M. F. de. Patologias ocasionadas pela umidade nas edificações. 2008. 64p. Monografia (Especialização). Universidade federal de Minas Gerais. 2008.

TOMAZ, P. C. A preservação do patrimônio cultural e sua trajetória no Brasil. Revista de história e estudos culturais. São Paulo, v. 7, n. 2, p. 01-12, 2010.

TUTIKIAN, B.; PACHECO, M. Inspección, Diagnóstico y Prognóstico en la Construcción Civil. In: BOLETÍN TÉCNICO. ALCONPAT INTERNACIONAL, 2013. p. 1-17. 